\title{
湖北崇阳地区二叠纪-三叠纪之交的介形虫化石 及其对灭绝事件的响应
}

\author{
刘浩 ${ }^{(1)}$, 王永标 ${ }^{(1)}$ ，袁爱华 ${ }^{(1)}$, 杨浩 ${ }^{(1)}$ ，宋海军 ${ }^{(1)}, 弓$ 素新 ${ }^{(2)}$ \\ (1) 中国地质大学生物地质与环境地质教育部重点实验室, 武汉 430074; \\ (2) 中国地质大学地质过程与矿产资源国家重点实验室, 武汉 430074 \\ * 联系人, E-mail: wangyb@cug.edu.cn \\ 收稿日期: 2009-06-30; 接受日期: 2010-01-04 \\ 国家自然科学基金(批准号: 40730209, 40830212, 40572002)和高等学校学科创新引智计划(编号: B08030)资助
}

\begin{abstract}
摘要在湖北崇阳二叠系-三叠系界线附近地层中共获得 400 余个介形虫实体标本, 归属 4 科 10 属 30 种. 其中在二叠纪末生物大灭绝界线之下长兴组灰岩中发现 6 属 20 种, 大灭绝 界线之上微生物岩中发现 7 属 11 种. 崇阳微生物岩中的介形虫化石与前人在广西和重庆地 区微生物岩中发现的介形虫不但在属种类型上存在差别, 而且可作为海水含氧量指标的滤 食性分子所占的比例也明显不同, 反映出华南地区二叠纪末生物大灭绝后古海洋环境的多 样性. 在纵向地层序列上, 崇阳剖面介形虫化石的分布具有明显的阶段性. 在大灭绝界线之 下 $200 \mathrm{~cm}$ 处部分介形虫已开始消失, 界线附近再次遭受灭绝, 在灭绝界线之上微生物岩的 顶部部分属种再度消失. 崇阳剖面介形虫的这种分阶段、多幕式演化规律表明, 在二叠纪三叠纪之交这一全球重大地质转折期, 作为大灭绝后仅存的几类多细胞生物的介形虫所遭 受的损失是个逐渐变化的过程. 碳同位素测试分析也显示, 古海洋环境的变化早在大灭绝 界线之下 $200 \mathrm{~cm}$ 处就已开始. 碳同位素曲线的波动与介形虫属种类型的变化和消失相关, 但与介形虫化石的丰度变化没有必然联系.
\end{abstract}

关键词

介形虫

微生物岩

二叠系-三叠系

大灭绝

湖北崇阳
二叠纪末的生物大灭绝是显生宙最大的灭绝事 件, 导致了 $90 \%$ 以上海洋物种的消失 ${ }^{[1,2]}$. 介形虫作 为灭绝事件后仅存的几类多细胞生物之一 ${ }^{[3]}$, 在研究 这一全球事件的性质和过程上具有重要的科学价值.

在 20 世纪 80 90 年代, 我国学者在晚二叠世及 二叠纪-三叠纪之交的介形虫化石研究上已积累了不 少成果 ${ }^{[4 \sim 14]}$. 但上述这些研究工作主要集中在一般浅 海碳酸盐岩沉积或滨浅海碎屑岩相剖面上.

近年来, 随着二叠纪-三叠纪界线附近钙质微生
物岩的发现, 许多学者开始关注这套形成于浅水潮 间带附近的特殊碳酸盐岩的成因和生态环境 ${ }^{[15 ~ 19]}$. 现有研究表明, 在这套直接产出在灭绝界线之上的 微生物岩中, 除了丰富的微生物化石外, 尚有大量的 介形虫化石和小型腹足类化石. 这些残存下来的多 细胞生物化石也就成了研究重大地质突变期生物与 环境的重要载体. 然而, 由于国内微生物岩的研究刚 刚起步和微生物岩中化石处理难度大等原因, 华南 地区微生物岩中的介形虫化石尚缺乏系统的研究.

引用格式: Liu H, Wang Y B, Yuan A H, et al. Ostracod fauna across the Permian-Triassic boundary at Chongyang, Hubei Province, and its implication for the process of the mass extinction. Sci China Earth Sci, 2010, doi: 10.1007/s11430-010-0045-8 
Crasquin-Soleau 等 ${ }^{[20,21]}$ 曾分别对重庆和广西地区微 生物岩中的介形类做过研究, 但样品较少, 工作尚不 系统.

本文通过酸蚀法对湖北崇阳剖面二叠纪生物大 灭绝界线上下的微生物岩和正常灰岩中的介形虫作了 系统的处理分析, 取得了丰富的介形虫化石, 为研究 大灭绝后残存期的生物与环境过程提供了新的材料.

\section{1 地质背景}

湖北崇阳二叠纪-三叠纪之交地层剖面出露良好, 大灭绝界线清晰. 杨浩等 ${ }^{[16]}$ 曾在该剖面大灭绝界线 之上发现牙形石化石 Hindeodus parvus, H. typicalis 和 H. latidentatus, 为二叠系-三叠系地层界线的确定 提供了依据. 大灭绝界线之下为晚二叠世长兴组厚 层至块状的生物碎屑颗粒灰岩(图 1), 产晚二叠世的 古纺缍蜓化石 Palaeofusulina. 长兴组灰岩中生物化 石及碎屑颗粒含量可达 $80 \%$, 生物化石种类丰富, 包 括各种钲藻、蜓、非蜓有孔虫、棘皮动物、苔蘚虫和 腕足动物碎片等, 反映正常的浅海碳酸盐台地相沉 积环境. 微生物岩则直接产出在大灭绝界线之上. 与 下伏长兴组生物碎屑灰岩相比, 微生物岩在结构构 造上具有明显的特殊性, 以具有花斑状构造的“凝块 石”为主, 局部出现“树枝状”构造的树形石. 二叠纪 末的生物大灭绝事件在微生物岩中留下了深刻的记 录, 灭绝事件导致了微生物岩中生物化石的种类和 数量发生了急剧的变化. 钙藻、蜓、苔藓虫、棘皮动 物、绝大部分的非蜓有孔虫和腕足动物已经消失. 经 过大量的岩石薄片观察, 微生物岩的主要特征是具 有丰富的微生物化石, 仅存的几类多细胞生物类型 极为单调, 主要为介形虫和腹足类. 然而, 这些大灭 绝后残存下来的多细胞生物却是我们研究和探索二 叠纪末大灭绝后古海洋环境的重要载体.

\section{2 化石处理方法和处理结果}

本次研究在崇阳剖面生物灭绝界线之下采集生 物碎屑灰岩样品 9 个, 生物灭绝界线之上采集微生物 岩及鲕粒灰岩样品 15 个. 对上述样品进行酸蚀法 ${ }^{[20]}$ 处理, 在其中 5 个层位的样品(样品号分别为 cy-200, cy-3, cy581, cy746 和 cy786) 中取得 440 余个介形虫实 体标本(图 1). 经鉴定, 这些介形虫化石分别归属于
10 属 30 个种(图 2 和 3).

\section{3 介形虫化石组合特征}

崇阳剖面二叠纪末大灭绝界线上下地层中的介 形虫具有明显不同的组合特征. 灭绝界线下 $200 \mathrm{~cm}$ 处以土菱介科 Bairdiidae 占大多数, 主要包括土菱介 属(Bairdia)、金星土菱介属(Bairdiacypris)和直土菱介 属(Rectobairdia), 主要分子有 Bairdia cf. beedei, Bairdia spp., Bairdiacypris fornicata, Bairdiacypris cf. fornicata, Bairdiacypris sp. sensu Crasquin-Soleau (2006), Bairdiacypris cf. ottomanensis 和 Rectobairdia cf. tantilla. 此外, 还有赛伦介属的 Silenites lenticularis.

灭绝界线下 $3 \mathrm{~cm}$ 处发现土菱介科(Bairdiidae)和 美花介科(Cytherideidae)的介形虫化石. 其中土菱介 科中以土菱介属(Bairdia) 占多数, 同时含少量金星土 菱介属 (Bairdiacypris). 主要分子有 Bairdia sp., Bairdia wailiensis, Bairdia cf. wailiensis, Bairdia cf. whitesidei 和 Bairdiacypris cf. ottomanensis. 美花介科 的介形虫在数量上仅次于土菱介科, 但属种单一, 仅 发现小巴氏介属(Basslerella), 包括 Basslerella obesa 和 Basslerella sp.两个种.

在生物大灭绝界线之上为厚约 $705 \mathrm{~cm}$ 的微生物 岩. 可能受大灭绝事件的影响, 微生物岩下部普遍缺 乏介形虫化石, 但在其上部(灭绝界线之上 $581 \mathrm{~cm}$ 处) 则产丰富的介形虫化石. 与灭绝界线之下的介形虫 组合相比, 微生物岩中土菱介科(Bairdiidae)的介形虫 数量仍然比较丰富, 但面貌已发生了很大变化. 除了 土菱介属(Bairdia)的一些分子 Bairdia cf. beedei 和 Bairdia sp.外, 出现了豆星介属(Fabalicypris)的一些种 类, 如 Fabalicypris venusta 和 Fabalicypris sp. 除土菱 介科外, 微生物岩中还发现似星介科(Paracyprididae) 似星介属的分子, 如 Paracypris sp. sensu Hao (1992), 化石数量也比较丰富.

微生物岩之上为厚约 $188 \mathrm{~cm}$ 的鲕粒灰岩. 一些 学者将鳁粒灰岩也划归为微生物岩的一种 ${ }^{[22,23]}$, 本 文为了与下伏具有豹皮状构造的典型微生物岩区别, 特将其单独划出. 鳁粒灰岩中土菱介科(Bairdiidea) 的数量和种类最多, 但以金星土菱介属 Bairdiacypris 为主, 没有发现土菱介属 (Bairdia), 主要分子 有 Bairdiacypris ottomanensis, Bairdiacypris cf. ottomanensis, Bairdiacypris spp. 此外, 还发现一些直 


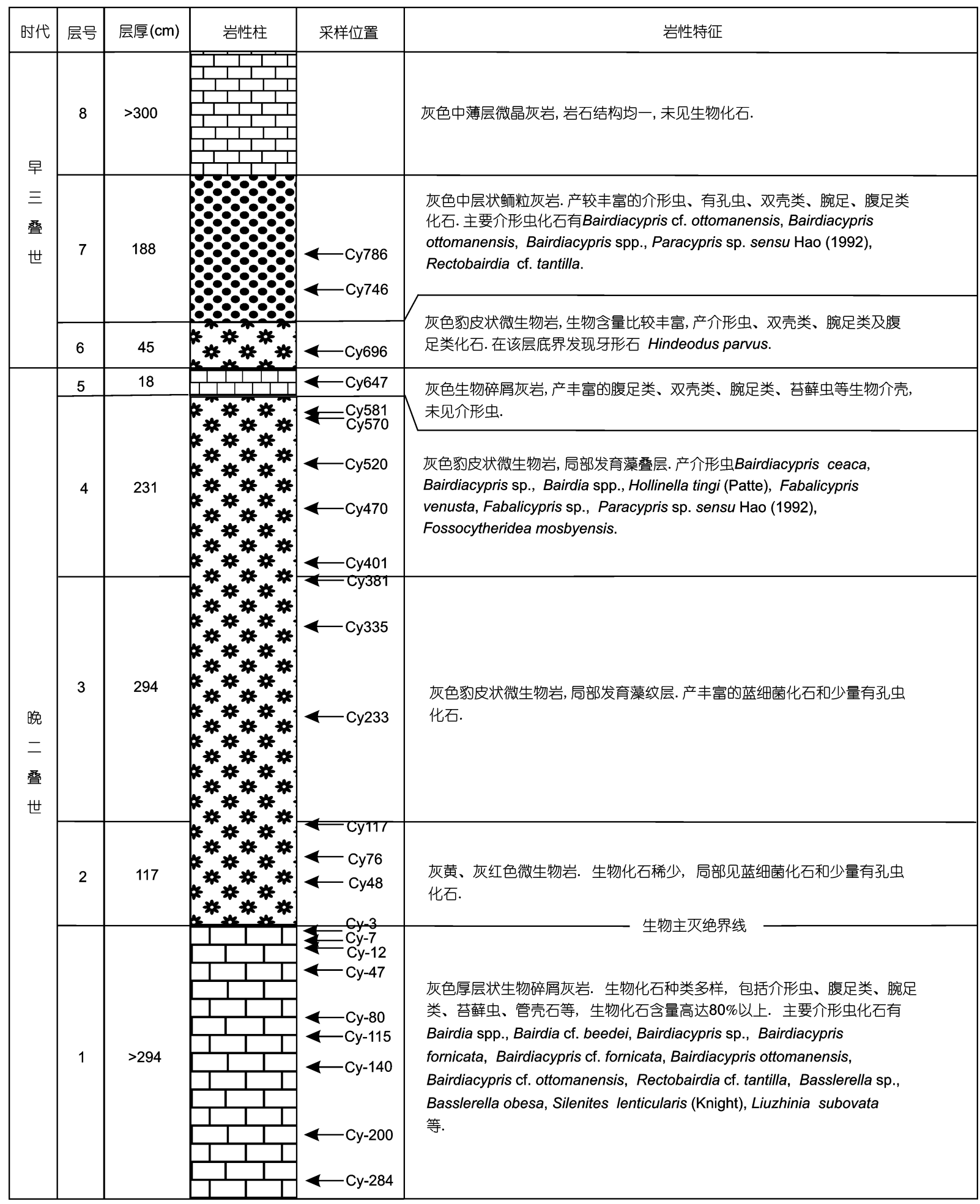

图 1 湖北崇阳二叠系-三叠系界线地层序列及介形虫化石采样位置 


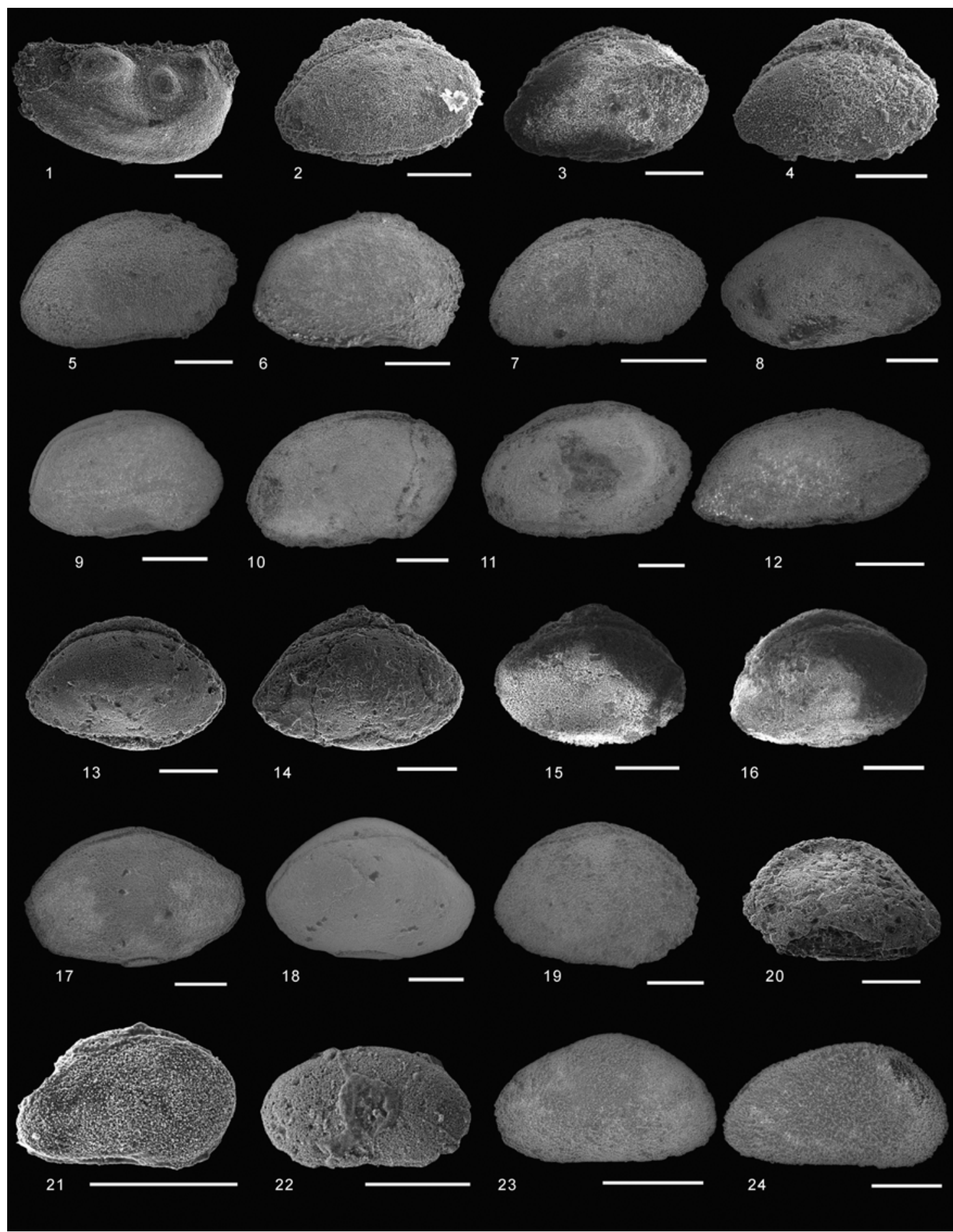

图 2 湖北崇阳二叠系-三叠系界线地层的介形虫化石

1. Hollinella tingi (Patte), 右侧视; 2 4. Bairdia cf. beedei Ulrich \& Bassler, 1906, 右侧视; 5 6. Bairdia wailiensis Crasquin-Soleau, 2006, 右侧视; 7. Bairdia cf. wailiensis Crasquin-Soleau, 2006, 右侧视; 8. Bairdia cf. whitesidei Bradfield, 1936, 左侧视; 9. Bairdia sp. sensu Wang, 1978, 右侧 视; 10 11. Bairdia sp. 1, 右侧视; 12. Bairdia sp. 2, 右侧视; 13 14. Bairdia sp. 3, 右侧视; 15 16. Bairdia sp. 4, 右侧视; 17. Bairdia sp. 5, 右侧 视; 18 19. Bairdia sp. 6, 右侧视; 20 21. Rectobairdia cf. tantilla (Kummerow), 右侧视和左侧视; 22. Bairdiacypris? caeca Shi, 1987, 左侧视; 23. Bairdiacypris fornicata Shi, 1987, 右侧视; 24. Bairdiacypris cf. fornicata Shi, 1987, 右侧视. 线条比例尺长度均为 $200 \mu \mathrm{m}$ 


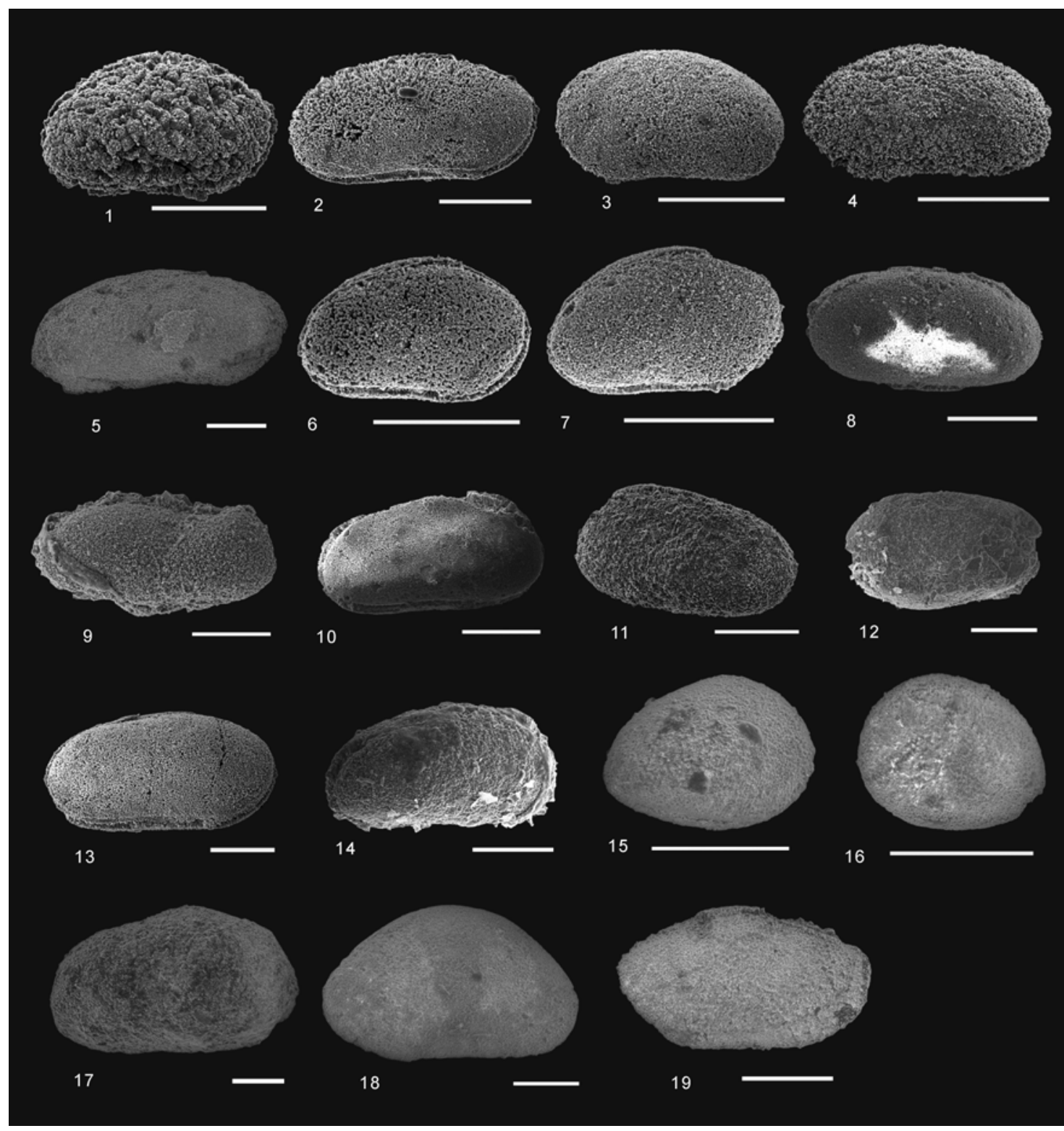

图 3 湖北崇阳二叠系-三叠系界线地层的介形虫化石

1. Bairdiacypris ottomanensis Crasquin-Soleau, 2004, 右侧视; 2. Bairdiacypris cf. ottomanensis Craquin-Soleau, 2004, 右侧视; 3 4. Bairdiacypris sp. 1, 左侧视; 5. Bairdiacypris sp. sensu Crasquin-Soleau, 2006, 右侧视; 6 7. Bairdiacypris sp. 2, 右侧视; 8. Fabalicypris sp., 右侧视; 9 10. Fabalicypris venusta Guan, 1985, 左侧视和右侧视; 11 13. Paracypris sp. sensu Hao, 1992, 左侧视、右侧视和右侧视; 14. Fossocytheridea mosbyensis Tibert, 2007, 右侧视; 15. Basslerella obesa sensu Chen \& Shi, 1982, 右侧视; 16. Basslerella sp., 右侧视; 17. Liuzhinia subovata

Zheng, 1976, 右侧视; 18. Silenites lenticularis (Knight), 右侧视; 19. Bairdiidae gen. et sp. indet., 右侧视. 线条比例尺长度均为 $200 \mu \mathrm{m}$

土菱介属的分子 Rectobairdia cf. tantilla 和似星介属 的分子 Paracypris sp. sensu Hao (1992).

总之, 崇阳剖面二叠纪-三叠纪之交不同层位中 的介形虫具有明显不同的组合特征. 从数量上说, 灭 绝界线之下的介形虫以土菱介科(Bairdiidae)的土菱
介属(Bairdia)为主，美花介科(Cytherideidae)的小巴 氏介属(Basslerella) 次之; 微生物岩中的介形虫以土 菱介科的土菱介属和似星介科(Paracyprididae)的似 星介属(Paracypris) 的种数最多, 亦有少量的金星土 菱介属(Bairdiacypris)；而鲕粒灰岩中的介形虫以金 
星土菱介属的丰度最高, 土菱介属的含量较低.

\section{4 华南不同地区微生物岩中介形虫化石的 对比}

前人在二叠纪和三叠纪非微生物岩相剖面中做 过许多介形虫的研究工作 ${ }^{[4,6,8,9,12 \sim 14]}$, 但微生物岩中 介形虫的研究工作刚刚起步, 目前仅局限在广西金 牙和重庆老龙洞两个剖面. 通过对湖北崇阳微生物 岩剖面介形虫的研究, 发现湖北崇阳、重庆老龙洞和 广西金牙微生物岩中的介形虫化石在组成上具有一 定的共性，但不同地区仍具有各自的一些特点.

崇阳剖面微生物岩中共发现介形虫 4 科 7 属 11 种, 土菱介科(Bairdiidae)的种类和数量均最多, 包括 土菱介属 Bairdia, 金星土菱介属 Bairdiacypris, 豆星 介属 Fabalicypris 及直土菱介属 Rectobairdia, 共计 8 种, 占总种数的 $72 \%$. 似星介科(Paracyprididae)、荷 尔介科(Hollinacea)和美花介科(Cytherideidae)均只有 1 属 1 种. 从生态习性中分析, 上述介形虫中滤食性 分子仅有 Hollinella tingi (Patte), 占微生物岩中总种 数的 9\%, 其他均为食碎屑物(deposit feeder)的介形虫.

重庆老龙洞剖面微生物岩中介形虫共 4 科 4 属 5 种 ${ }^{[20]}$, 其中土菱介科只有金星土菱介属的一个种 Bairdiacypris ottomanensis; 似星介科只有似星介属 的 Paracypris sp. sensu Hao (1992); Cytherissinellidae 只有美花介属的 Callicythere postiangusta; Knoxiatidae 只有狼蒂介属的两个种, Langdaia laolongdongensis 和 L. suboblonga Wang (1978). 上述介形虫中的 Callicythere postiangusta, Langdaia laolongdongensis 和

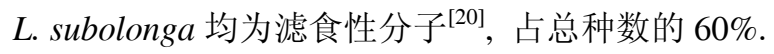

广西金牙和外里剖面微生物岩中发现介形虫 6 属 12 种 ${ }^{[21]}$, 其中土菱介科最多, 包括 Bairdia 和 Bairdiacypris 两属 7 种, 约占 58\%. 似星介科只有似 星介属(Paracypris)的两个种. 此外, 还有 Healdia, Kerocythere 和 Liuzhinia 各 1 属 1 种. 与重庆老龙洞 剖面不同, 广西金牙剖面中滤食性分子只有赫鲁特 介 Healdia sp., 约占介形虫总数的 $7 \%$.

上述研究表明, 广西、重庆和湖北崇阳三个地区 微生物岩中不但在介形虫类型组成上存在差别, 而 且滤食性分子和食碎屑物分子所占比例也明显不同. Lethiers 和 Whatley ${ }^{[24]}$ 曾建立了介形虫生物群中滤食 性分子所占比例与水体中氧含量关系的模型, 发现
滤食性分子所占比例越高, 水体中氧含量越低. Crasquin-Soleau 和 Kershaw ${ }^{[20]}$ 对重庆老龙洞剖面微生 物岩中介形虫的研究显示, 该剖面中介形虫种类单 调, 滤食性分子所占比例高, 达 $60 \%$, 反映贫氧环境 (Dysoxia). 而广西微生物岩中介形虫种类多样, 滤食 性分子所占比例低, 占 7\%, 认为属于正常充氧的海 洋环境 ${ }^{[21]}$. 导致上述两地区介形虫组成及水体含氧 量差异的原因可能与当时不同的古地理位置有关 ${ }^{[19]}$. 晚二叠世-早三叠世之交, 重庆地区在古地理位置上 属于相对闭塞的古特提斯洋, 而广西南盘江地区则 面向开阔的泛大洋. 然而, 在二叠纪-三叠纪之交, 虽 然湖北崇阳与重庆同样位于相对闭塞的古特提斯洋, 但其介形虫生物群中滤食性分子却只占 $9 \%$, 与广西 地区的非常接近(占 $7 \%$ ), 因此并不反映明显的缺氧 环境. 这说明二叠纪-三叠纪之交即使同处于古特提 斯洋的湖北崇阳和重庆地区在介形虫组成和海洋环 境上仍有明显的差别, 反映了华南地区二叠纪末生 物大灭绝后古海洋环境的多样性.

\section{5 介形虫动物群对灭绝事件的响应}

二叠纪末的全球生物灭绝事件导致了 $90 \%$ 以上 的海洋生物的消失 ${ }^{[1]}$. 湖北崇阳剖面同样记录了这一 影响深远的地质事件. 蜓类、棘皮、苔藓虫、四射珊 瑚、海绵、钙藻及绝大部分的腕足类在大灭绝界线之 上的微生物岩中已不再出现. 除了丰富的微生物化 石外, 幸存下来的多细胞生物主要为介形虫和小型 腹足类. 然而, 崇阳剖面的研究显示, 即使像介形虫 这类生存能力较强的生物在这一全球事件中也遭受 了明显的影响. 在大灭绝界线之上微生物岩中介形虫 化石的组成与灭绝前的面貌发生了很大的变化. 灭绝 界线下的生物碎屑灰岩中发现 6 属 20 种, 而在界线附 近消失的有 5 属 16 种, 仅有 3 属 4 种穿越了灭绝界线. 灭绝界线上的微生物岩和鲕粒灰岩中共发现 7 属 14 种, 其中 6 个属的 10 个种为灭绝事件后新出现的种.

需要指出的是, 虽然华南许多剖面的微生物岩 中具有丰富的介形虫化石, 介形虫的丰度似乎没有 减小, 甚至还出现大量的富集, 但是介形虫的种类 (或分异度)已发生显著下降. 微生物岩中介形虫丰度 的提高可能与大量多细胞生物的灭绝为介形虫提供 了更大的生存空间有关.

尽管二叠纪末全球事件对生物界造成的深刻影 
响已是众所周知的事实, 但不同学者对这一事件的 性质和过程却有不同的解释。一些学者认为这是一 次突发而快速的地外灾难事件, 生物的灭绝也主要 集中发生在某一界面上 ${ }^{[25,26]}$; 然而也有一些学者主 张二叠纪末的全球事件源自地内, 期间生物灭绝是 个多幕的过程 ${ }^{[2730]}$.

从崇阳剖面介形虫的分布来看, 早在灭绝界线 之下 $200 \mathrm{~cm}$ 处相当一部分介形虫就已经消失(图 4). 从灭绝界线下 $200 \mathrm{~cm}$ 开始消失的介形虫主要是土菱 介属(Bairdia) 和金星土菱介属(Bairdiacypris)的一些 分子, 包括 Bairdia spp., Bairdiacypris fornicata, Bairdiacypris cf. fornicata 和 Bairdiacypris sp. sensu
Crasquin-Soleau (2006). 此外还有 Silenites lenticularis (Knight)等.

在紧邻灭绝界线处, 介形虫再次遭受重创(图 4). 从灭绝界线下 $3 \mathrm{~cm}$ 开始, 消失的介形虫主要是土菱 介属 Bairdia 和小巴氏介属 Basslerella. 包括 Bairdia wailiensis, Bairdia cf. wailiensis, Bairdia sp. sensu Wang (1978), Bairdia cf. whitesidei, Basslerella obesa sensu Chen \& Shi (1982)和 Basslerella sp. 此外, 还有 Liuzhinia subovata. 本次灭绝事件影响深远, 包括 蜓、珊瑚、海绵、海百合、腕足等在内的绝大部分海 洋无脊椎动物遭受灭绝, 取而代之的是在大灭绝界 线之上形成了一套结构和构造均非常特殊的微生物

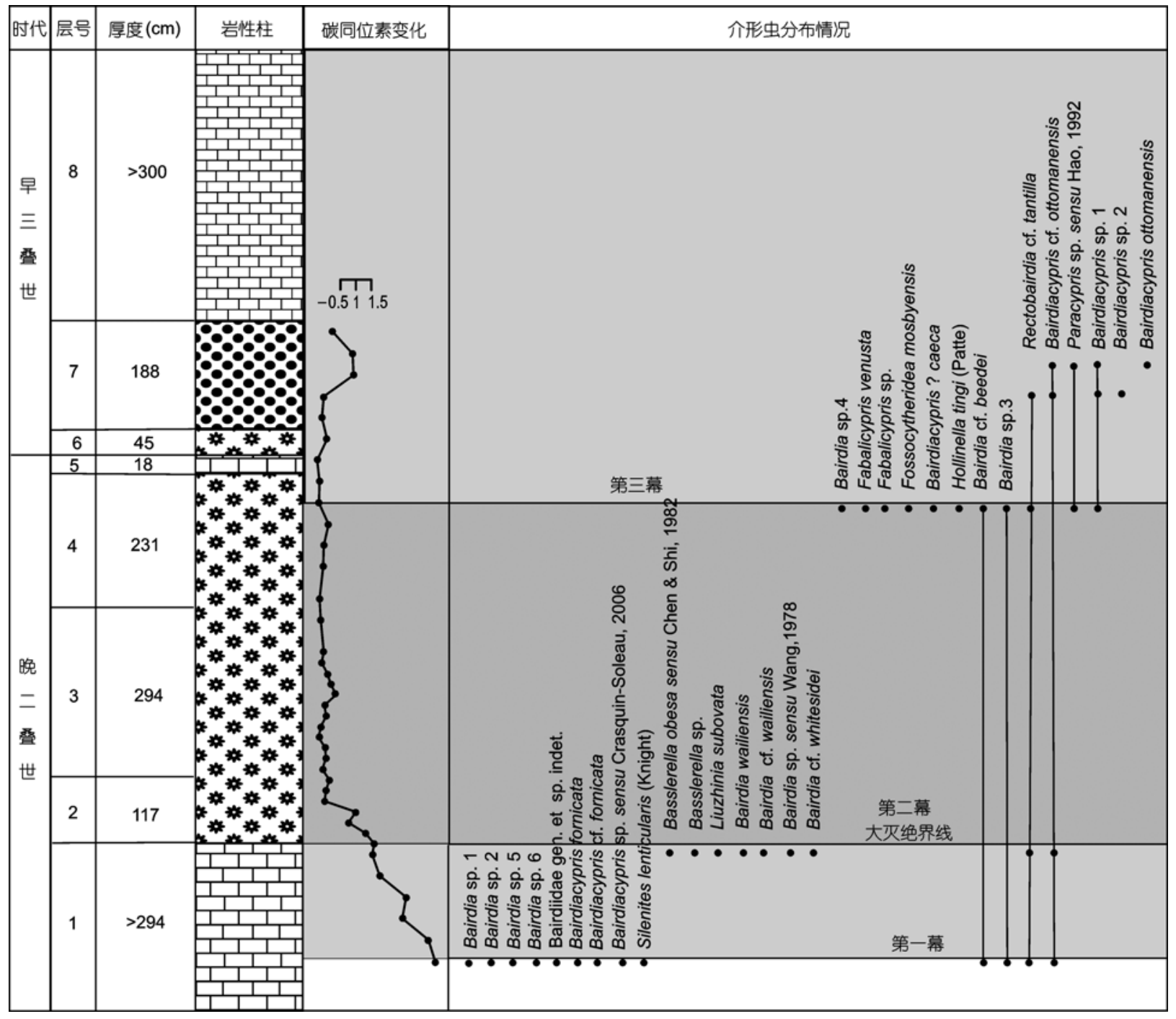

图 4 湖北崇阳二叠系-三叠系界线附近的介形虫化石群演变与碳同位素变化 
岩. 虽然微生物岩底部的生物大灭绝界线在整个华 南地区均十分清晰, 但界线则非常平整, 许多学者认 为期间是个连续的沉积过程, 不存在地层的缺 失 ${ }^{[31 ~ 33]}$. 需要指出的是, 尽管介形虫和小型腹足类 是微生物岩中的主要多细胞生物化石, 但崇阳剖面 微生物岩的下部除了蓝细菌化石外, 普遍缺乏介形 虫化石.

在接近微生物岩顶部(灭绝界线之上 $581 \mathrm{~cm}$ ), 则 首次出现数量丰富的介形虫化石 (图 4). 但其上很快 过渡为一套鲕粒灰岩, 同时该层位(第 4 层)的大部分 介形虫也消失.

崇阳剖面介形虫的演替至少可以分出上述 3 个 阶段. 经过 3 个阶段的变化, 残存并穿过界线的介形 虫只有 Bairdia cf. beedei, Bairdia sp. 3, Rectobairdia cf. tantilla 和 Bairdiacypris cf. ottomanensis. 经资料对 比，这 4 个种在华南地区其他剖面上尚未发现.

在崇阳剖面生物大灭绝界线之下, 部分介形虫 就已开始消失, 说明二叠纪-三叠纪之交重大地质事 件的发生早在主灭绝界线之前就开始启动. 碳同位 素测试分析也表明二叠纪-三叠纪之交碳同位素的负
偏早在灭绝界线之下 $200 \mathrm{~cm}$ 的层位就已开始(图 4). 之后, 介形虫化石群经过几个阶段的演替, 最后残存 下来的属种已为数不多. 崇阳剖面二叠纪-三叠纪之 交介形虫化石和碳同位素的这种分布规律表明，在 二叠纪-三叠纪之交的重大地质转折期, 无论是生物 化石还是碳同位素所反映的古海洋环境均是多幕式 的变化过程, 而不是一次性的生物灭绝事件.

需要指出的是, 虽然介形虫种类的变化和灭绝 过程与碳同位素的变化存在对应关系, 但介形虫丰 度的变化与碳同位素曲线的波动之间似乎没有必然 关系. 在整个微生物岩段, 虽然碳同位素值均很低, 但在微生物岩的上部介形虫的丰度很高, 下部则普 遍缺乏介形虫化石, 因此介形虫化石丰度的变化与 碳同位素的波动没有关系, 而可能与藻纹层的发育 程度有关. 崇阳剖面微生物岩下部普遍发育藻纹层 构造, 而上部则主要呈“花斑状构造”. 吴亚生等 ${ }^{[29]}$ 所 报道的贵州紫云地区二叠系-三叠系界线附近地层中 似乎也存在类似的现象. 在藻纹层不发育的泥晶灰 岩中可见介形虫、小腹足类和丰富的虫孔, 但在发育 藻纹层构造的泥晶灰岩中则缺乏生物化石.

\section{参考文献}

1 Erwin D H. The Permo-Triassic extinction. Nature, 1994, 367: 231-236

2 Alroy J. Dynamics of origination and extinction in the marine fossil record. Proc Natl Acad Sci USA, 2008, 105: 11536-11542

3 Crasquin-Soleau S, Galfetti T, Bucher H, et al. Ostracod recovery in the aftermath of the Permian-Triassic crisis: Palaeozoic-Mesozoic turnover. Hydrobiologia, 2007, 585: 13-27

4 王尚启. 黔西滇东北晚二叠世及早三叠世介形类化石. 古生物学报, 1978, 17: 277-308

5 卫民. 四川早、中三叠世介形类. 古生物学报, 1981, 20: 501-507

6 陈德琼, 施从广. 江苏南通、湖北泟阳晚二叠世介形类. 中国科学院南京地质古生物研究所丛刊, 1982, 4: 105-152

7 关绍曾. 鄂西中三叠海相介形虫. 微体古生物学报, 1985, 2: 169-178

8 施从广, 陈德琼. 浙江长兴煤山长兴组介形类. 中国科学院南京地质古生物研究所, 编. 中国各系界线地层及古生物一二叠系与 三叠系界线(一). 南京: 南京大学出版社, 1987. 23-80

9 施从广, 陈德琼. 广西合山、宜山晚二叠世介形类. 中国科学院南京地质古生物研究所从刊, 2002, 15: 47一 129

10 郝维城. 贵州早三叠世介形类. 微体古生物学报, 1992, 9: 37-44

11 郝维城. 贵州晚二叠世-早三叠世介形虫动物群的演变. 地质论评, 1994, 40: 67-91

12 伊武军. 福建大田东坑晚二叠世晚期及早三叠世早期介形类动物群. 古生物学报, 1992, 2: 103-114

13 伊武军. 福建大田广平早二叠世栖霞组介形类动物群. 古生物学报, 1993, 32: 561-586

14 伊武军. 福建大田崆峒山晚二叠世和早三叠世介形类. 古生物学报, 2004, 43: 566-570

15 王永标, 童金南, 王家生, 等. 华南二叠纪末大绝灭后的钻质微生物岩及古环境意义. 科学通报, 2005, 50: 552一 558

16 杨浩, 张素新, 江海水, 等. 湖北崇阳二叠纪-三叠纪之交钻质微生物岩的时代及基本特征. 地球科学, 2006, 31 : $165-170$ 
17 姜红霞, 吴亚生. 重庆二叠系-三叠系界线地层微生物岩新认识. 岩石学报, 2007, 23: 1189-1196

18 吴亚生, 姜红霞, Yang W, 等. 二叠纪-三叠纪之交缺氧环境的微生物和微生物岩. 中国科学 D 辑: 地球科学, 2007, 37: 618一628

19 Kershaw S, Li Y, Crasquin-Soleau S, et al. Earliest Triassic microbialites in the South China Block and other areas: Controls on their growth and distribution. Facies, 2007, 53: 409—425

20 Crasquin-Soleau S, Kershaw S. Ostracod fauna from the Permian-Triassic boundary interval of South China (Huaying Mountains, eastern Sichuan Province): Palaeoenvironmental significance. Palaeogeogr Palaeoclimatol Palaeoecol, 2005, 217: 131—141

21 Crasquin-Soleau S, Galfetti T, Bucher H, et al. Palaeoecological changes after the end-Permian mass extinction: Early Triassic ostracods from northwestern Guangxi Province, South China. Riv Ital Paleontol Stratigr, 2006, 112: 55—75

22 Burne R V, Moore L S. Microbialites: Organosedimentary deposits of benthic microbial communities. Palaios, 1987, 2: 241-254

23 戴永定, 陈孟莪, 王尧. 微生物岩研究的发展与展望. 地球科学进展, 1996, 11: 210-215

24 Lethiers F, Whatley R. The use of ostracoda to reconstruct the oxygen levels of the Late Paleozoic oceans. Mar Micropaleontol, 1994, 24: $57-69$

25 Rampino M R, Prokoph A, Adler A. Tempo of the end Permian event: High-resolution cyclostratigraphy at the Permian-Triassic boundary. Geology, 2000, 28: 643-646

26 Jin Y G, Wang Y, Wang W, et al. Pattern of marine mass extinction near the Permian-Triassic boundary in South China. Science, 2000, 289: $432-436$

27 Xie S C, Pancost R D, Yin H F, et al. Two episodes of microbial change coupled with Permo/Triassic faunal mass extinction. Nature, 2005, 434: 494-497

28 Yin H F, Feng Q L, Lai X L, et al. The protracted Permo-Triassic crisis and multi-episode extinction around the Permian-Triassic boundary. Glob Planet Change, 2007, 55: 1-20

29 吴亚生, 范嘉松, 姜红霞, 等. 二叠纪末生物礁生态系绝灭的方式. 科学通报, 2007, 52: 207-214

30 Song H J, Tong J N, Chen Z Q. Two episodes of foraminiferal extinction near the Permian-Triassic boundary at the Meishan section, South China. Aust J Earth Sci, 2009, 56: 765-773

31 Lehrmann D J. Early Triassic calcimicrobial moundsand biostromes of the Nanpanjiang basin, South China. Geology, 1999, 27: 359-362

32 Ezaki Y, Liu J B, Anachi N. Earliest Triassic microbialite micro-megastructure in the Huaying area of Sichuan Province, South China: Implications for the nature of oceanic conditions after the end-Permian extinction. Palaios, 2003, 18: 388—402

33 Payne J L, Lehrmann D J, Follett D, et al. Erosional truncation of uppermost Permian shallow-marine carbonates and implications for Permian-Triassic boundary events. Geol Soc Am Bull, 2007, 119: 771-784 